\title{
Referral rates for diagnostic testing support an incidence of permanent neonatal diabetes in three European countries of at least 1 in 260,000 live births
}

\author{
A. S. Slingerland • B. M. Shields • S. E. Flanagan • \\ G. J. Bruining • K. Noordam • A. Gach • W. Mlynarski • \\ M. T. Malecki • A. T. Hattersley $\cdot$ S. Ellard
}

Received: 17 March 2009 / Accepted: 6 May 2009/Published online: 5 June 2009

(C) The Author(s) 2009. This article is published with open access at Springerlink.com

Keywords Genetic testing $\cdot$ Incidence $\cdot$ Monogenic diabetes $\cdot$ Neonatal diabetes $\cdot$ PNDM

\section{Abbreviation \\ PNDM Permanent form of neonatal diabetes mellitus}

To the Editor: Surveys of neonatal diabetes in the UK and Germany from more than a decade ago reported an incidence of 1 in 400,000-450,000 live births [1, 2]. The permanent form of neonatal diabetes mellitus (PNDM) accounted for about half the cases, equating to a PNDM incidence of 1 in $800,000-900,000$ live births. The definition of neonatal diabetes used in these publications was a diagnosis of diabetes within 4 weeks [1] or 6 weeks [2] of birth. HLA genotype analysis has shown that permanent diabetes diagnosed within the first 6 months of life is PNDM rather

A. S. Slingerland $\cdot$ B. M. Shields $\cdot$ S. E. Flanagan

A. T. Hattersley $(\bowtie) \cdot$ S. Ellard

Institute of Biomedical and Clinical Sciences,

Peninsula Medical School,

Exeter EX2 5DW, UK

e-mail: andrew.hattersley@pms.ac.uk

\section{A. S. Slingerland}

Department of Cardiology, Leiden University Medical Centre,

Leiden, the Netherlands

\author{
A. S. Slingerland \\ Care Cure Science Foundation, \\ Amsterdam, the Netherlands \\ G. J. Bruining \\ Department of Paediatrics, Maxima Medical Centre, \\ Veldhoven, the Netherlands
}

than type 1 diabetes [3]. Using a definition of diagnosis before 6 months, the incidence of PNDM was recently calculated at 1 in 214,000 live births from the Slovakian diabetes register [4]. We examined the incidence rates of PNDM in three further European countries.

The incidence of neonatal diabetes for a country can be calculated from the referral rate of cases to a diagnostic laboratory and the annual birth rate, if all cases are referred to that laboratory. This will be less than the true incidence if not all cases are referred, but will still reflect a minimum incidence. In 2001 the Exeter Peninsula Molecular Genetics Laboratory based at the Royal Devon and Exeter Hospital (Exeter, UK) began recruiting patients worldwide prior to the discovery reported in 2004 that KCNJ11 mutations are the most common cause of PNDM [5]. The highest referral rates are in the UK, the Netherlands and Poland, where there have been considerable educational initiatives to inform clinicians of the free-of-charge diagnostic service

\section{K. Noordam}

Department of Paediatrics, Radboud University Medical Centre, Nijmegen, the Netherlands

A. Gach $\cdot$ W. Mlynarski

Department of Paediatrics, 1st Institute of Paediatrics, Medical University of Lodz,

Lodz, Poland

M. T. Malecki

Department of Metabolic Diseases, Jagiellonian University Medical College, Krakow, Poland 
for patients diagnosed with diabetes before 6 months of age. Between 2001 and 2009, samples from 119 patients (50.4\% male) born between 1950 and 2005, diagnosed with PNDM and with no documented remission from diabetes were referred from the UK, the Netherlands and Poland. Isolated diabetes occurred in 60 patients, three had pancreatic agenesis, six had features consistent with WolcottRallison syndrome and 40 had neurological symptoms. A genetic diagnosis was obtained in 59 cases, with mutations in KCNJ11 $(n=32)$ and INS $(n=10)$ being the most common. All the procedures in the participating centres were conducted in accordance with the Declaration of Helsinki as revised in 2000, and patients or their guardians gave written informed consent.

We calculated the minimum annual PNDM incidence rate from 1950 to 2005 for the UK, the Netherlands and Poland. This was calculated using the number of patients referred who were born in a given year and dividing by the number of live births in that year using data from the United Nations Population Division (http://esa.un.org/ unpp/, accessed 1 March 2009). To avoid large influences of stochastic variation that could occur with the low numbers, the results from the three countries were combined and the data were analysed in 5 year groups from 1950 to 2005. Minimum observed PNDM incidence ranged from $<0.5$ cases per million live births between 1950 and 1970, to about one case per million between 1970 and 1985, and increased between 1985 and 2005 from 1.9 to 3.8 cases per million (Fig. 1).
The most recent data ( 24 cases born between 2000 and 2005 ) showed an incidence of 3.8 cases per million live births (one in 260,000) and this is comparable to the 4.6 cases per million live births calculated from the eight cases reported to the Slovakian registry between 1981 and 2004 [4]. An incidence of at least one in 260,000 live births in these four European countries is still much lower than in Oman, which has the highest reported incidence of PNDM, with one in 45,000 live births between 1991 and 1995 [6]. In Oman, consanguineous marriages are frequent (55\%) and consequently we would expect a high prevalence of recessive forms of PNDM, which are rare in outbred populations.

The reported incidence of neonatal diabetes in Germany (12 cases between 1977 and 1991) and the UK (two cases in 1994 and 1995) was considerably lower at 1 in 400,000450,000 live births [1, 2], which corresponds to a PNDM incidence of about 1 in 800,000-900,000 live births, as approximately $50 \%$ of the neonatal diabetes cases remit. One partial explanation is that the definition of neonatal diabetes for these series was diagnosis in the first 4 or 6 weeks rather than the first 6 months of life. In our dataset, $62 \%$ of patients had been diagnosed before 7 weeks. The finding that patients diagnosed with diabetes in the first 6 months have mutations in the PNDM-associated genes [7] and a similar prevalence of type 1-predisposing HLA genotypes as non-diabetic controls [3] strongly supports the view that a cut-off of 6 months is appropriate.

The major limitation of our study is that the data were taken from a single referral centre, to which all referrals were
Fig. 1 Minimum observed annual incidence of PNDM per million live births per year for 5 year intervals from 1 January 1950 to 31 December 2004 in Poland, the Netherlands and the UK combined

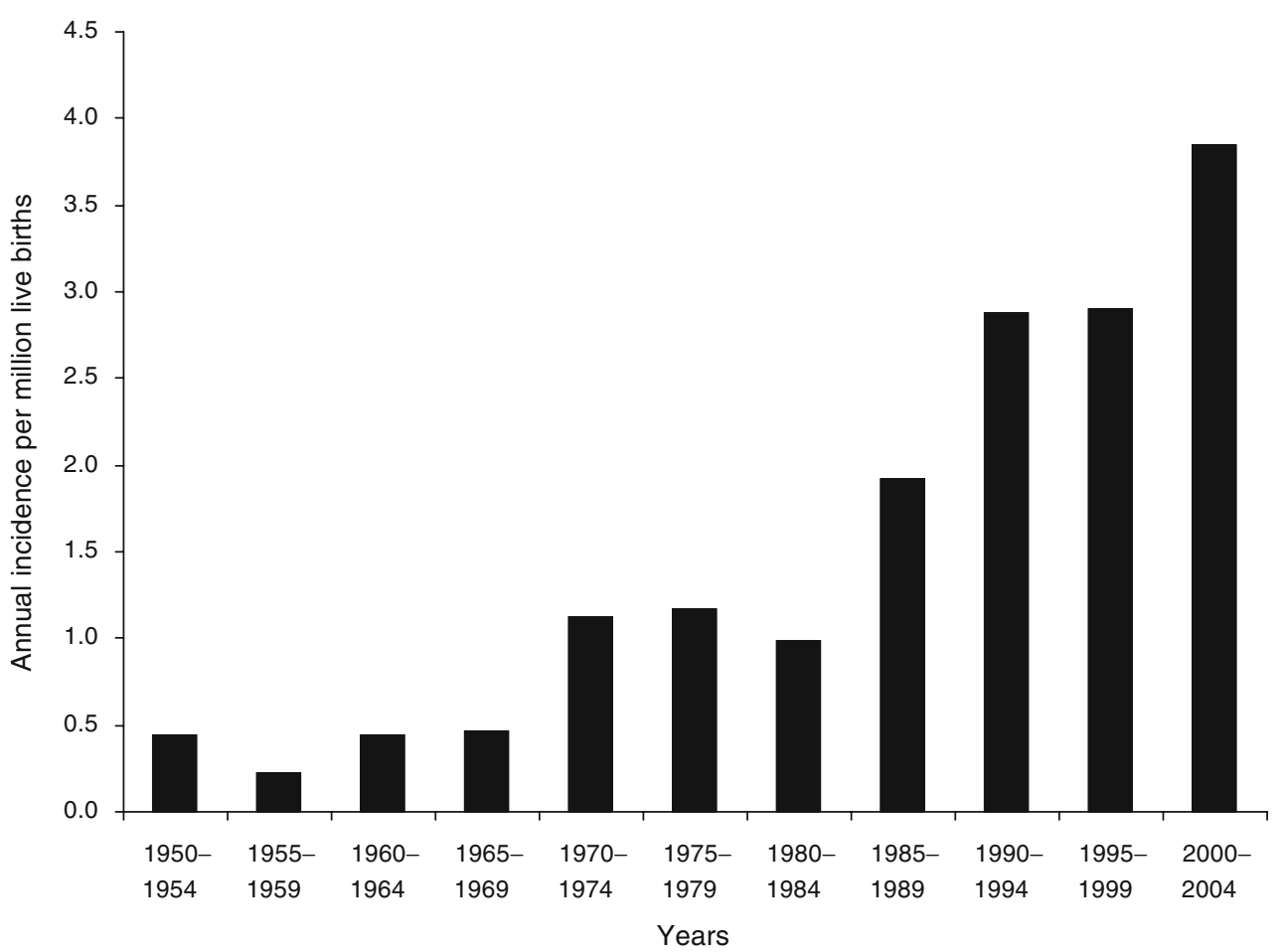


voluntary. We consider it likely that we identified all patients from these three countries who had genetic testing for PNDM during this time period. However, we could not ascertain patients with PNDM who died or for other reasons were not referred for genetic testing. The calculated incidence data therefore represent the minimum incidence rather than the actual incidence and will be an underestimate.

The incidence of PNDM, based on referral rates for genetic testing, appears to have progressively increased over time (Fig. 1) and was particularly low before 1985 . This has many possible explanations. It could reflect increased survival with improved clinical care over time. However, the uncertainty about the referral rates for genetic testing means that the apparent increase in incidence over time may in fact merely reflect a difference in the proportion of cases referred. In support of this being a factor, we noted that $66 \%$ of the patients were born after 1985 and were therefore likely to have been referred from a paediatric rather than an adult clinic. Paediatricians are more aware of recent advances in the genetic aetiology of PNDM and the impact this has on treatment, with improved control in approximately $90 \%$ of patients with ATPsensitive $\mathrm{K}^{+}$channel $\left(\mathrm{K}_{\text {АTP }}\right.$ channel) mutations when insulin is replaced by sulfonylureas $[8,9]$. In addition the smaller numbers of patients in paediatric clinics make it easier to identify those patients diagnosed before 6 months and refer them for genetic testing. Adult patients with PNDM are probably under-diagnosed and more effort should be made to identify these patients, especially as some may benefit from transfer from insulin to sulfonylurea treatment.

In conclusion, based on genetic testing the recent incidence of PNDM in the UK, the Netherlands and Poland is at least 1 in 260,000 live births, in keeping with a recent smaller study from Slovakia. This is considerably higher than in previous incidence studies performed in the UK and Germany 10 years ago. This is only partly explained by the widening of the diagnostic age group and therefore suggests in addition either increased survival or greater awareness of the diagnosis resulting from the therapeutic advances seen since the discovery of $\mathrm{K}_{\mathrm{ATP}}$ channel mutations.

Acknowledgements We wish to thank all patients, their families, nurses and doctors. We thank A.-M. Patch (Peninsula Medical School, Exeter, UK) for her contribution to this study. The Child Health and
Well-being Fund and J. Wouter Jukema, Department of Cardiology, Leiden University Medical Centre, Leiden, the Netherlands provided support for A. S. Slingerland. M. T. Malecki was supported by the Polish Ministry of Education and Science (Grant No. 2 P0E 136 29) and funds from the Jagiellonian University Medical College (Grant K/ZDS/000399). B. M. Shields and S. Ellard are employed as core staff within the National Institute of Health Research, UK-funded Peninsula Clinical Research Facility. S. E. Flanagan was funded by the Sir Graham Wilkins PMS research studentship and A. T. Hattersley is a Wellcome Trust Research Leave Fellow.

Duality of interest The authors declare that there is no duality of interest associated with this manuscript.

Open Access This article is distributed under the terms of the Creative Commons Attribution Noncommercial License which permits any noncommercial use, distribution, and reproduction in any medium, provided the original author(s) and source are credited.

\section{References}

1. von Mühlendahl KE, Herkenhoff H (1995) Long-term course of neonatal diabetes. N Engl J Med 333:704-708

2. Shield JPH, Gardner RJ, Wadsworth EJK et al (1997) Aetiopathology and genetic basis of neonatal diabetes. Arch Dis Child 76: F39-F42

3. Edghill EL, Dix RJ, Flanagan SE et al (2006) HLA genotyping supports a nonautoimmune etiology in patients diagnosed with diabetes under the age of 6 months. Diabetes 55:1895-1898

4. Stanik J, Gasperikova D, Paskova M et al (2007) Prevalence of permanent neonatal diabetes in Slovakia and successful replacement of insulin with sulfonylurea therapy in KCNJ11 and ABCC8 mutation carriers. J Clin Endocrinol Metab 92:1276-1282

5. Gloyn AL, Pearson ER, Antcliff JF et al (2004) Activating mutations in the gene encoding the ATP-sensitive potassiumchannel subunit Kir6.2 and permanent neonatal diabetes. N Engl J Med 350:1838-1849

6. Bappal B, Raghupathy P, de Silva V, Khusaiby SM (1999) Permanent neonatal diabetes mellitus: clinical presentation and epidemiology in Oman. Arch Dis Child Fetal Neonatal Ed 80: F209-F212

7. Flanagan SE, Edghill EL, Gloyn AL, Ellard S, Hattersley AT (2006) Mutations in KCNJ11, which encodes Kir6.2, are a common cause of diabetes diagnosed in the first 6 months of life, with the phenotype determined by genotype. Diabetologia 49:1190-1197

8. Pearson ER, Flechtner I, Njolstad PR et al (2006) Switching from insulin to oral sulfonylureas in patients with diabetes due to Kir6.2 mutations. N Engl J Med 355:467-477

9. Rafiq M, Flanagan SE, Patch AM, Shields BM, Ellard S, Hattersley AT (2007) Effective treatment with oral sulfonylureas in patients with diabetes due to SUR1 mutations. Diabetes Care 31:204-209 